nal software such as drug dosing calculation software or medical diagnostic software to identify acid-base disorders from arterial blood gas data. Other monitors allow seamless transfer of data from bedside monitor to transport monitor, and back to the bedside simply by moving a data module.

The next few years will likely witness a continuing boom in the use of computer technology in the OR, but do not expect that the systems will always be easy to use.

D. John Doyle MD PhD FRCPC

Toronto, Ontario

\section{Review of Airway Cam Video Series Volume 2: Pediatric Intubation}

27 min; \$150 (US); written and produced by Richard M. Levitan, Scott Cook-Sather, 1998.

VHS NTSC format. www.airwaycam.com

This is the second in an excellent series of instructional videos by Richard M. Levitan using the Airway $\mathrm{Cam}^{\mathrm{TM}}$ as means of recording real intubations. The first tape in the series, dealing with intubation in adults, received excellent reviews, so I was curious as to whether or not Levitan would succeed once again. I was not disappointed.

A six-step approach to intubation is presented and repeatedly emphasized to drive home the fundamental teaching message. The main anatomical differences between adult and pediatric airways are explained, along with a discussion concerning the equipment differences that stem from anatomical differences. Rules for selecting laryngoscope type and size, as well as guidelines for selecting endotracheal tube type and size are well covered. As with the first video, the emphasis is on learning by example, and we are offered clip after clip of pediatric airway views along with superb quality (indeed, professional) narration describing what is going on. Freeze frames, arrows, and graphics highlight key landmarks and teaching points.

This excellent teaching resource deserves a place in the video library of every anesthesia department. I eagerly await further videos from Dr. Levitan.

D. John Doyle MD PhD FRCPC

Toronto, Ontario

\section{Erratum}

Gray C, Swinhoe CF, Myint $\Upsilon$, Mason D. Target controlled infusion of ketamine as analgesia for TIVA with propofol. Can J Anesth 1999; 46: 957-61.

An error was made in Table I Pharmacokinetic parameters of ketamine used for computer model, page 958 (October issue). The same values to $k_{21}$ and $\mathrm{k}_{12}$ were erroneously assigned. The correct values should be:

$$
\begin{array}{lll}
\mathrm{k}_{21} & 0.01473 \pm 0.003 & \min ^{-1} \\
\mathrm{~K}_{12} & 0.03296 \pm 0.005 & \min ^{-1}
\end{array}
$$

